Revue d'histoire de l'Amérique française

REVUE D.HISTOIRE DE L'AMÉRIQUE FRANÇAISE

\title{
La rébellion de 1837 et les modèles théoriques de l'émergence de la nation et du nationalisme
}

\section{Marcel Bellavance}

Volume 53, numéro 3, hiver 2000

URI : https://id.erudit.org/iderudit/005326ar

DOI : https://doi.org/10.7202/005326ar

Aller au sommaire du numéro

Éditeur(s)

Institut d'histoire de l'Amérique française

ISSN

0035-2357 (imprimé)

1492-1383 (numérique)

Découvrir la revue

Citer cet article

Bellavance, M. (2000). La rébellion de 1837 et les modèles théoriques de l'émergence de la nation et du nationalisme. Revue d'histoire de l'Amérique française, 53(3), 367-400. https://doi.org/10.7202/005326ar
Résumé de l'article

Cet article propose une interprétation de la rébellion de 1837 à la lumière du grand courant libéral et nationalitaire européen. En s'inspirant des modèles théoriques de l'émergence de l'État-nation et du nationalisme, l'auteur essaiera en effet de dégager une typologie applicable à l'expérience canadienne. Il se demande si, ce qui a été présenté jusqu'ici comme singulier dans l'historiographie, ne relèverait pas plutôt de l'universel. 


\section{LA RÉBELLION DE 1837 ET LES MODÈLES THÉORIQUES DE L'ÉMERGENCE DE LA NATION ET DU NATIONALISME ${ }^{1}$}

MARCEL BELLAVANCE

Université de Sherbrooke

\section{RÉSUMÉ}

Cet article propose une interprétation de la rébellion de 1837 à la lumière du grand courant libéral et nationalitaire européen. En s'inspirant des modèles théoriques de l'émergence de l'État-nation et du nationalisme, l'auteur essaiera en effet de dégager une typologie applicable à l'expérience canadienne. Il se demande si, ce qui a été présenté jusqu'ici comme singulier dans l'historiographie, ne relèverait pas plutôt de l'universel.

\section{ABSTRACT}

This article proposes an interpretation based on the European liberal et national movement. Starting from the theorical models of the Nation building and nationalism, the author tries to develop a typology applicable to the Canadian experience. He asks if what has been described in the historiography until now as particular is not really universal.

À l'encontre de tous les peuples des deux Amériques qui étaient parvenus au statut d'État-nation, le Canada est le seul pays américain à ne pas avoir réalisé son indépendance au $\mathrm{XIX}^{\mathrm{e}}$ siècle. Cette défaite se répercuta dans l'inconscient collectif canadien, en particulier dans l'historiographie de la rébellion de 1837-1838 qui fit une large place à la problématique de l'échec et à la recherche des coupables chez les vaincus.

Cette manière de river souvent l'analyse de la rébellion de 1837 à l'événement et de la concevoir presque toujours dans le singulier nous paraissait limitée. Elle la privait, nous semblait-il, du champ fécond de compréhension que lui aurait ouvert une perspective univer-

1. Cet essai est une version revue et corrigée d'une conférence donnée à Dublin et à Cork en Irlande, les 20 et 22 mai 1998.

RHAF, vol. 53, $\mathrm{n}^{\circ}$ 3, hiver 2000 
selle. Une telle mise en perspective nous indiquait une voie de recherche pertinente qui a été rarement empruntée, comme on peut le constater à la lecture du dossier historiographique préparé par Jean-Paul Bernard $^{2}$ et à celle des ouvrages spécialisés sur la question publiés depuis lors. C'est cette voie que nous avons retenue, quant à nous, dans la rédaction de l'essai d'histoire comparée que nous préparons actuellement. Nous abordons aujourd'hui quelques volets importants de cette recherche en confrontant la rébellion de 1837 au Canada et son historiographie, aux modèles explicatifs d'émergence de l'Étatnation et du «nationalisme» en Europe principalement, à la même époque.

Le présent article comprend trois parties: la première jette un regard large sur le courant libéral et nationalitaire en Europe et au Canada; la deuxième entend rendre compte des principaux modèles théoriques de l'émergence de l'État-nation qui existent actuellement; la dernière, enfin, mettra en parallèle ces modèles et les interprétations les plus connues de l'historiographie de la rébellion.

LE COURANT LIBÉRAL ET NATIONALITAIRE DE 1789 À 1914 L'«ÂAE DU NATIONALISME»

Quiconque entreprend l'étude du XIX ${ }^{\mathrm{e}}$ siècle européen prend vite la mesure de la position dominante et agissante du libéralisme comme courant de pensée révolutionnaire et de la portée tout aussi profonde du principe corollaire des nationalités et du droit des peuples à disposer d'eux-mêmes comme normes universelles de référence et d'existence pour toute communauté humaine constituant un peuple. Le courant libéral et démocratique, de même que le mouvement des nationalités furent d'une telle amplitude qu'ils ont défini chacun à leur façon le siècle tout entier. En y associant la révolution industrielle qui «a agi de pair ${ }^{3} »$, ils constituèrent les quatre grandes vagues qui «dessinent la trame de l'histoire politique et sociale du $\mathrm{XIX}^{\mathrm{e}}$ siècle $^{4} »$.

Le caractère inédit de ces courants est si vrai qu'il a fini par distinguer l'époque où ils se manifestèrent. Âge du nationalisme, âge du capital, ère du libéralisme, risorgimento, «âge de la religion de la liberté », autant de qualificatifs qui s'imposent d'eux-mêmes à la cons-

2. Jean-Paul Bernard, Les Rébellions de 1837-1838. Les patriotes du Bas-Canada dans la mémoire collective et chez les historiens (Montréal, Boréal Express, 1983).

3. Guy Hermet, Histoire des nations et du nationalisme en Europe (Paris, Seuil, 1996), 67-68.

4. René Rémond, Introduction à l'histoire de notre temps, 2: Le XIX ${ }^{e}$ siècle (Paris, Seuil, 1971), 174. 
cience historique ${ }^{5}$. Les expressions «siècle des nationalités » et «siècle des révolutions» nous sont aussi très familières, de même que les élans, démocratiques ici, républicains là, patriotiques ailleurs, qui les inspirèrent. Ces expressions nous renvoient donc spontanément à cette période dont «l'essentiel du contenu» serait défini par la «formation des nations ${ }^{6} \gg$.

La nationalisation et la libéralisation des sociétés, ou comme dirait Benedetto Croce, le long mouvement « de la liberté libérale à la liberté démocratique ${ }^{7} »$, se sont effectuées par phases ${ }^{8}$, par vagues ${ }^{9}$ et "accès de fièvre ${ }^{10}$ », de la révolution française, alors que «l'ordre ancien commence à s'écrouler ${ }^{11}$ », à la Première Guerre mondiale où l' «internationale des nations », quelle que soit la forme de l'État que ces nations épousent, s'impose désormais comme phénomène capital de notre époque. Un examen attentif de cette évolution, qui s'inspire des trois phases du fait national et libéral établies par Jean-Yves Guiomar et Nicolas Rousselier, nous permettra de bien situer la rébellion de 1837 au Canada par rapport à la chronologie du courant libéral et national et de souligner la pertinence de l'approche combinatoire dans l'étude de ces phénomènes, à l'instar des historiens, politologues, sociologues et anthropologues qui ont développé jusqu'à maintenant des modèles théoriques explicatifs de l'émergence des nationalités.

Ces trois phases du fait national, que nous voulons évoquer rapidement, vont de la fin du XVIII ${ }^{\mathrm{e}}$ siècle au «printemps des peuples » de 1848 pour la première, de l'échec des révolutions de 1848 à la Grande Guerre pour la deuxième et occupent tout le $\mathrm{XX}^{\mathrm{e}}$ siècle pour la troisième. Seules les deux premières phases de cette évolution nous intéressent parce qu'elles sont contemporaines à la rébellion de 1837 qui relève du même phénomène de nationalisation et de libéralisation des sociétés.

5. Ernest Gellner, Nations and Nationalism (Ithaca, New York, Cornell University Press, 1987). Traduction française sous le titre de Nations et nationalisme (Paris, Payot, 1989); Eric Hobsbawm, L'ère du capital (Paris, Fayard, 1970); id., Nations et nationalisme depuis 1870. Programme, mythe et réalité (Paris, Gallimard, 1992); Nicolas Rousselier, L'Europe des libéraux (Bruxelles, Éditions Complexes, coll. «Questions au XX ${ }^{\mathrm{e}}$ siècle», 1991; R. Rémond, op. cit.; Benedetto Croce, Histoire de l'Europe au XIX $X^{e}$ siècle (Paris, Gallimard, coll. «Essai », 1991).

6. Walter Bagehot cité par Eric Hobsbawm, op. cit., 35-36.

7. B. Croce, op. cit.

8. Jean-Yves Guiomar, «Le nationalisme face à la démocratie», dans Antoine de Baeque, dir., Une histoire de la démocratie en Europe (Paris, Éditions Le Monde, 1991), 52-74.

9. R. Rémond, op. cit., 8.

10. G. Hermet, op. cit., 135.

11. J.-Y. Guiomar, op. cit., 53. 
Le libéralisme caractéristique de la première phase du fait national et démocratique que la majorité des auteurs associent au libéralisme politique, est un état d'esprit ${ }^{12}$ qui anime les libéraux dans toutes leurs luttes contre les contraintes imposées par les monarchies de droit divin et pour «l'élargissement de la sphère de liberté individuelle»par rapport à $l^{\prime}$ État $^{13}$. "La démocratie à l'aube de son règne, écrit Burdeau, s'affirme moins comme une appropriation du Pouvoir par le peuple que comme une libération de l'homme à l'égard de l'État ${ }^{14}$.» Les six libertés (liberté religieuse, liberté d'association, liberté de presse, liberté d'enseignement, libertés locales, liberté de suffrage) revendiquées par le courant libéral dans sa quête pour l'établissement de régimes constitutionnels et représentatifs, sont contenues pour l'essentiel dans le concept de «liberté libérale » que Croce pose comme fondement de la liberté démocratique et, aussi, de la liberté nationale dans les cas où l'«affranchissement de la domination étrangère » était nécessaire ${ }^{15}$.

En prétendant, en effet, déplacer la source et la légitimité du pouvoir du monarque absolu vers le peuple, les libéraux opposaient à la souveraineté du roi la souveraineté nationale, qu'ils ne concevaient que dans le cadre d'institutions parlementaires dont le fonctionnement devait être inscrit dans une constitution. Ce courant se manifeste très tôt aux États-Unis qui firent leur indépendance en 1776 et adoptèrent une constitution fédérale en 1787. Il connaît un succès retentissant en France après 1789 avec l'établissement du régime représentatif; en Angleterre où le parlementarisme évolua vers le gouvernement responsable (réforme de 1832), et partout dans la «Jeune Europe », c'està-dire en Italie, en Irlande, en Pologne, en Grèce, dans les Balkans et sur la Baltique où la haine de la domination étrangère attisa le sentiment de liberté nationale ${ }^{16}$. Il atteint aussi le Canada, dès 1776, sous l'influence du républicanisme américain ${ }^{17}$ et, en 1791, quand le régime parlementaire fut instauré. «Le Bas-Canada au tournant du XIX 1978).

12. Francis-Paul Bénoit, La démocratie libérale (Paris, Presses universitaires de France,

13. Georges Burdeau, L'État libéral et les techniques de la démocratie gouvernée (Paris, Librairie générale de droit et de jurisprudence, 1987), 6: 37; Norberto Bobio, Libéralisme et démocratie (Paris, Les Éditions du Cerf, 1996), 28.

14. G. Burdeau, op. cit., 6: 53.

15. N. Bobio, op. cit., 59 .

16. Otto Bauer, La question des nationalités et la social- démocratie (Montréal/Paris, Guérin littérature/Études et Documentation Internationales — Arcantère Éditions, 1987), 1: 199200.

17. Louis-Georges Harvey, «Le mouvement patriote comme projet de rupture (18051837)», dans Gérard Bouchard et Yvan Lamonde, dir., Québécois et Américains. La culture québécoise aux XIXe et XXe siècles (Saint-Laurent, Fides, 1995). 
siècle, a pu écrire J.-P. Wallot, participe aux transformations économiques, politiques, sociales et idéologiques qui ébranlent les fondements du monde atlantique ${ }^{18}$.»

Cette période de l'histoire, qui va de la Révolution américaine et française aux révolutions européennes de 1848 pendant laquelle l'État de droit s'imposa aux monarchies, confère au courant libéral son caractère constitutionnel et nationalitaire. Ce constitutionnalisme caractérise le libéralisme de cette période, de même que l'idée de souveraineté nationale qui lui est intimement liée. Le peuple souverain, incarnation de la nation, se présente comme la source et la légitimité du pouvoir des États entre lesquels la concurrence économique doit s'exercer.

Cette première phase du courant libéral et national contrairement à la deuxième, aurait été «peu marquée politiquement par les questions culturelles », en particulier par la langue ${ }^{19}$. La révolution politique survint d'abord et surtout dans des pays déjà unifiés comme la France et à unifier comme l'Allemagne et l'Italie et dans des colonies de même langue que leur métropole comme les États-Unis et tous les pays de l'Amérique latine qui firent leur indépendance sur fond de rivalités entre les bourgeoisies «créoles», donc d'origine européenne, et les bourgeoisies métropolitaines.

Il est intéressant de se rappeler également que les libéraux de cette époque ne réservaient le statut d'Etat-nation qu'aux seuls peuples ayant atteint un seuil de développement jugé acceptable. Ils pensaient aux grandes nationalités comme la France, l'Espagne, l'Angleterre et aux grandes cultures italienne et allemande qui existaient bien avant leur intégration politique et économique. (On comprend mieux ainsi l'attitude méprisante de lord Durham pour qui le Bas-Canada n'était qu'un résidu de la grande nation française.) L'indépendance de la Belgique en 1831 et celle de la Grèce en 1832 représentaient une première entorse à cette règle du seuil qui était loin de faire l'unanimité, surtout dans les trois Empires multinationaux, l'Empire des Habsbourg, l'Empire ottoman et l'Empire des tsars, menacés de désintégration sous l'action conjuguée des forces démocratiques et nationales et des mouvements patriotiques dans les pays qu'ils dominaient.

Vers 1840, des communautés de langues diverses «entrent en hostilités et tendent à constituer des nationalités différente ${ }^{20} »$. Par-

18. Jean-Pierre Wallot, «Frontières ou fragments du système atlantique : des idées étrangères dans l'identité bas-canadienne au début du XIX ${ }^{\mathrm{e}}$ siècle», Communications historiques 1983, 1-29.

19. J.-Y. Guiomar, op. cit., 54.

20. Paul de Bourgoing, dans J.-Y. Guiomar, op. cit., 54. 
tout, en effet, l'association entre liberté politique, liberté nationale, égalité civile et justice sociale d'une part et, d'autre part, l'aspiration à l'unité et à l'indépendance nationales semblaient converger ${ }^{21}$. Le principe des nationalités et le droit des peuples à l'autodétermination s'imposent alors comme le trait dominant de cette deuxième phase du fait national et libéral. Malgré la défaite des révolutions de 1848 à Paris, Berlin, Naples, Vienne, Prague, Budapest, Bucarest, Dublin, etc., le libéralisme refit sa cohésion autour du principe des nationalités et de l'élargissement du suffrage. La répression de ces révolutions, avant tout sociales, ne remit pas en cause la question nationale. Le prince Louis-Napoléon, premier chef d'État élu au suffrage universel, donna à l'idée nationale une impulsion jusque-là inégalée. Il encouragea l'unification de l'Allemagne et de l'Italie et ébranla ainsi les grands empires incapables d'empêcher la naissance des petites nations alors qualifiées avec mépris, de «nations sans histoire». L'idée nationalitaire, qui veut qu'à chaque nation corresponde un État, domina jusqu'à la Première Guerre. Le seuil nécessaire à la vie d'un État qu'avait proposé Mazzini en 1830, puis rejeté avec la fondation de la Jeune Europe en 1837, fut abandonné22.

Ce survol du libéralisme et du fait national au XIX ${ }^{\mathrm{e}}$ siècle fait apparaître la compatibilité qui a existé entre l'autodétermination des peuples et des régimes politiques aussi différents que la monarchie constitutionnelle et la république. Il nous permet de situer aussi la question nationale québécoise dans le grand courant libéral et nationalitaire contemporain et de comprendre, par la même occasion, que cette question fut posée précocement dans des termes analogues.

La question nationale au Québec prend racine dès le traité de Paris de 1763 quand la Nouvelle-France passa officiellement sous contrôle étranger et s'intégra à un nouveau réseau d'échanges commerciaux dont les règles dictées par le mercantilisme lui étaient familières. L'empire britannique, à l'instar des empires français et espagnol, imposait à ses colonies les mêmes obligations et contraintes qui exigeaient d'elles l'exclusivité des rapports économiques et suscitaient immanquablement la même rivalité entre les marchands et les négociants coloniaux bien implantés dans le pays et les marchands métropolitains venus au pays pour s'enrichir. Ce système fut contesté partout dans les deux Amériques et la rivalité qu'il suscita entre coloniaux et métropolitains évolua partout, sauf au Canada, vers l'indépendance.

21. J.-Y. Guiomar, op. cit., 61 .

22. N. Rousselier, op. cit., 51; G. Hermet, op. cit., 158-159. 
La conquête britannique de la Nouvelle-France ne modifiait donc pas la nature des relations économiques de cette dernière avec la métropole qui étaient, comme avant 1763, dictées par le mercantilisme. Toutefois, il est à noter un fait crucial: le réseau et les acteurs contrôlant le réseau changèrent. Ce réseau devenait désormais exclusivement britannique, de même que les marchands, bailleurs de fonds et autres qui le contrôlaient. Le Canada se retrouvait ainsi dans une position unique dans les Amériques. Les antagonismes économiques, inhérents au mercantilisme, y étaient tout autant culturels. En effet, les rivalités économiques entre la métropole et sa colonie se répercutaient quotidiennement dans la vie coloniale elle-même du fait de la coexistence, d'une part, d'une élite de culture étrangère installée au pouvoir sous la protection d'une armée d'occupation et, d'autre part, d'une population française coupée depuis 1763 de sa métropole naturelle et écartée par conséquent du pouvoir économique et social.

Vers la fin du siècle, la population anglaise, nouvellement arrivée, vivait en majorité dans les villes et se composait presque essentiellement de fonctionnaires, de marchands et de militaires ${ }^{23}$. Aussi tôt qu'en 1774, les Britanniques affirmaient contrôler déjà $75 \%$ du commerce de la colonie ${ }^{24}$. En 1831, les marchands anglais à eux seuls possédaient $40 \%$ de tout le territoire seigneurial du Bas-Canada ${ }^{25}$ et l'armée comptait pour $28 \%$ de la population de la ville de Québec ${ }^{26}$. Cette situation particulière au Canada, par rapport aux autres colonies américaines, conférait au facteur culturel un rôle discriminatoire comparable à celui qu'il joua à l'aube du «printemps des peuples» quelques décennies plus tard. Elle fit en sorte que l'idéal libéral rejoignit rapidement ici l'idéal national, dès les années 1773-1783, sous l'influence des «libérateurs» américains et de propagandistes comme l'imprimeur Fleury Mesplet, du journaliste voltairien Valentin Jautard et du marchand Pierre Du Calvet ${ }^{27}$ et à l'occasion de l'instauration du régime parlementaire en 1791 qui institutionnalisait, tout en l'exacerbant, les conflits entre les Britanniques au pouvoir dans les Conseils et la majorité canadienne. «The whole country, écrivait sir George

23. Donald Creighton, Dominion of the North. A History of Canada (Toronto, Macmillan, 1966), 152

24. Fernand Ouellet, Histoire économique et sociale du Québec 1760-1850. Structure et conjoncture (Ottawa, Fides, 1966), 91.

25. Gérald Bernier et Daniel Salée, Entre l'ordre et la liberté. Colonialisme, pouvoir et transition vers le capitalisme dans le Québec du XIXe siècle (Montréal, Boréal, 1995), 84.

26. David-Thiery Ruddel et Marc Lafrance, «Québec, 1785-1840 : problèmes de croissance d'une ville coloniale», Histoire sociale/Social History, 18,36 (novembre 1985).

27. Gilles Gallichan, Livre et politique au Bas-Canada, 1791-1849 (Sillery, Septentrion, 1991), 45-46, 217; J.-P. Wallot, Un Québec qui bougeait, trame socio-politique du Québec au tournant du XIX $X^{e}$ siècle (Montréal, Boréal Express, 1973), 258-259. 
Prevost au Colonial Office en 1814, is by now divided into two parties, one the party of administration, the other that of the people ${ }^{28}$.»

Les luttes constitutionnelles, inévitables dans de telles conditions conflictuelles, évoluèrent vers la crise sous le gouvernement Craig $(1807-1811)^{29}$, puis débordèrent par la suite, de l'enceinte du Parlement pour se répandre dans la population qui se souleva en 1837 , selon un scénario comparable à ce qu'on pouvait observer ailleurs en Occident. Dans un tel contexte, bien analysé par Jean-Pierre Wallot ${ }^{30}$, le facteur national s'imposa de lui-même à la conscience collective, mettant en relief les «ingrédients » qu'Isaiah Berlin impute à tout fait national au $\mathrm{XIX}^{\mathrm{e}}$ siècle dont le plus important est «la croyance en la nécessité primordiale d'appartenir à une nation ${ }^{31} \gg$. Comme en Europe à la même époque, pour ne pas dire avant, le courant libéral et l'idée nationale cheminèrent ensemble et conférèrent au libéralisme canadien $\mathrm{du} \mathrm{XIX}^{\mathrm{e}}$ siècle toute son originalité.

«Les Canadiens, écrivait Garneau, avaient infiniment plus de droit de renverser leur gouvernement que n'en avaient eu l'Angleterre ellemême en 1688, et les États-Unis en 1775, parce que c'était contre leur nationalité, cette propriété la plus sacrée d'un peuple, que le bureau colonial dirigeait ses coups ${ }^{32}$.»

La crise politique qui advint sous Craig en début de siècle et la rébellion de 1837-1838 s'inscrivaient ainsi dans la même trajectoire de libéralisation et de nationalisation des sociétés occidentales. Même soif de liberté face au pouvoir, même quête de justice et de démocratie, même valorisation de la culture nationale, même recours à l'histoire et aux traditions, même émergence du sentiment et de la conscience nationale, même «imaginaire national» enfin, comme dirait Anderson $^{33}$. Les références idéologiques et chronologiques sont évidentes et concordantes. Il serait donc intéressant, pour cette raison, de soumettre le cas canadien aux différentes grilles d'analyse élaborées

28. H. Taft Manning, The Revolt of French Canada, 1800-1835: A Chapter in the History of the British Commonwealth (Toronto, Macmillan, 1962), 58.

29. J.-P. Wallot, op. cit., chap.IV, «La crise sous Craig», 143-168.

30. Ibid., 295-296; id., «Révolutions et réformisme dans le Bas-Canada (1773-1815)», Annales de la révolution française, 45 (1973); Gilles Paquet et Jean-Pierre Wallot, "Groupes sociaux et pouvoir: le cas canadien», Revue d'histoire de l'Amérique française, 27,4 (mars 1974).

31. Isaiah Berlin, «Le nationalisme: dédains d'hier, puissance d'aujourd'hui», dans À contre-courant. Essai sur l'Histoire des idées (Paris, Albin Michel, 1988), 361.

32. François-Xavier Garneau, Histoire du Canada (Paris, Librairie Félix Alcan, 19131920), 11: 652. Cinquième édition, revue, annotée et publiée [...] par son petit-fils Hector Garneau.

33. Benedict Anderson, L'imaginaire national. Réflexions sur l'origine et l'essor du nationalisme (Paris, La Découverte, 1996). 
depuis une trentaine d'années sur le sujet par des auteurs comme Stein Rokkan, Karl Deutsch, Ernest Gellner et Miroslav Hroch, pour rendre compte à la fois des analogies et des différences entre les rébellions d'ici et les mouvements nationaux d'indépendance en Europe. Déjà l'historien français Jacques Godechot en avait proposé la démarche lors du colloque sur «Le Canada et la Révolution atlantique », tenu à Montréal en $1969^{34}$. Il n'est pas tout, en effet, de juxtaposer les expériences historiques. Encore faut-il procéder à une véritable analyse combinatoire!

Il serait vain de chercher dans la production historienne présente sur la rébellion une référence significative à ces auteurs pourtant incontournables dont certains écrivent depuis plus de 40 ans. Le politologue Louis Balthazar ferait-il exception? Il est évident que dans son Bilan du nationalisme au Québec ${ }^{35}$, il emprunte à la théorie des communications et de la mobilisation sociale de Karl Deutsch, les éléments nécessaires à la définition des quatre formes de nationalisme qu'aurait connues le Québec de 1760 à nos jours.

D'un autre côté, rarement à notre connaissance, la démarche comparative élaborée par les théoriciens du fait national ne prit en compte le cas canadien. Rarement aussi, et c'est plus grave encore, l'historiographie canadienne et québécoise n'a tenté de s'inscrire dans une démarche qui irait au-delà de la simple référence contextuelle. Les vœux de Godechot sont donc restés sans lendemain. Il y a bien le collectif Mouvements nationaux d'indépendance et classes populaires aux XIX ${ }^{e}$ et XX $X^{e}$ siècles en Occident et en Orient ${ }^{36}$, publié en 1971, dans lequel Fernand Ouellet présenta l'interprétation des insurrections de 1837-1838 qu'il avait déjà exposée dans son Histoire économique et sociale [...] publiée en 1966 et, surtout, dans Histoire sociale deux ans plus tard. Cette invitation significative à associer les «insurrections de 1837-1838» aux mouvements nationaux d'indépendance fit encore ici long feu, Ouellet refusant d'associer insurrections et libéralisme nationalitaire. Ce n'est donc à vrai dire que tout récemment, soit en 1997, qu'un premier collectif sur le sujet a paru sous la direction de Gérard Bouchard et Yvan Lamonde. Intitulé La Nation dans tous ses États. Le Québec en comparaison, cet ouvrage fait appel à des auteurs venant d'Argentine, de Belgique, d'Espagne, des États-Unis et du Québec qui explorent certains aspects comparables de l'expérience nationale en Europe et dans les Amériques.

\footnotetext{
34. Pierre Tousignant, «Le conservatisme de la petite noblesse seigneuriale au Canada», Discussion, Annales de la Révolution française, 45 (1973): 340-341.

35. Louis Balthazar, Bilan du nationalisme au Québec (Montréal, Hexagone, 1986), 31.

36. (Paris, Armand Colin, 1971), 2 vol.
} 
L'ouverture amorcée par Wallot et poursuivie par les historiens Bouchard et Lamonde contraste toutefois avec le courant historiographique actuellement dominant au Canada qui a trop vite conclu au caractère conservateur et rétrograde de la rébellion de 1837, jugée à partir de concepts perçus aujourd'hui comme étant négatifs. Comment expliquer cela? Probablement par le fait qu'en ratant leur révolution libérale et nationale, les Canadiens rataient du même coup leur entrée véritable dans l'histoire ${ }^{37}$ et que, depuis lors, la question nationale ne se posera plus à la conscience historique en terme nationalitaire comme elle le fut ailleurs, mais seulement dans sa dimension interculturelle.

Notre historiographie, dans son ensemble, reflète encore cette perspective à tel point qu'ainsi comprise, la question nationale au Québec se trouve identifiée à un "nationalisme conservateur ${ }^{38}$ ", désormais «inconciliable avec un sain libéralisme ${ }^{39}$ », perdant par le fait même toute pertinence historique pour être réduite aux simples conflits interethniques qui persistent dans l'histoire canadienne depuis 1867. L'intérêt pour les rébellions résidera dès lors dans ce qui fut perçu comme leur caractère plus conservateur que libéral, et surtout plus conservateur parce que national. On crut également pouvoir y identifier un comportement plus ou moins manipulateur des patriotes. Il faut reconnaître toutefois que le livre de Gérald Bernier et de Daniel Salée $^{40}$ et la brochure de Jean-Paul Bernard ${ }^{41}$ sur les Rébellions rompent avec ce courant.

Chercher à savoir ce que les Rébellions de 1837-1838 partageaient avec les autres mouvements d'émancipation nationale à la même époque n'a pas été considéré non plus comme un sujet de recherche pertinent. L'excellente synthèse de l'historiographie des Rébellions produite par J.-P. Bernard est éloquente à cet égard ${ }^{42}$. Curieusement, deux historiens importants de la période, Fernand Ouellet et Allan Greer, ont esquivé ce rapprochement, privilégiant plutôt la comparaison avec le modèle des révoltes paysannes du XVII ${ }^{e}$ siècle que celui

37. Gellner, se référant à Hegel qui pensait que la période préétatique est aussi «préhistorique », ajoute : «il semblerait, selon cette idée, que l'histoire vraie d'une nation ne commence qu'au moment où elle acquiert un État. » E. Gellner, op. cit., 75-76. Nous citons d'après l'édition française.

38. John A. Dickinson et Brian Young, Brève histoire socio- économique du Québec (Sillery, Septentrion, 1992), 12.

39. F. Ouellet, dir., Papineau (Québec, Les Presses de 1'Université Laval, coll. «Cahiers de l'Institut d'histoire», [1959]), 47 et 99.

40. G. Bernier et D. Salée, op. cit.

41. J.-P. Bernard, Les rébellions de 1837 et de 1838 dans le Bas-Canada (Ottawa, La Société historique de Canada, Brochure $\left.\mathrm{n}^{\circ} 55,1996\right)$.

42. J.-P. Bernard, Les Rébellions de 1837-1838. Les patriotes du Bas-Canada..., op. cit. 
des révolutions libérales nationalitaires du $\mathrm{XIX}^{\mathrm{e}}$ siècle. Chez Ouellet, la démarche est consciente; chez Greer, elle l'est beaucoup moins. Chez ce dernier, les références aux révolutions libérales sont présentes; il en parle même souvent, mais ne les intègre pas pour autant dans son analyse. Nous y reviendrons. Quant à l'approche comparative qui est amorcée chez Bouchard et privilégiée dans notre projet de recherche, elle nous permettra de ramener la question nationale québécoise au niveau de l'universel et de la lier au courant libéral qui lui est contemporain.

La présentation de certains modèles explicatifs du fait national constituera l'essentiel de cette deuxième partie de notre étude. Nous n'avons toutefois pas l'intention d'en faire une présentation exhaustive. Nous nous limiterons plutôt aux grandes orientations et aux paradigmes dominants qui caractérisent ces modèles. Nous nous arrêterons plus précisément sur les approches à la fois globalisantes et pertinentes pour éclairer la question québécoise et en dégagerons les traits communs. Enfin, en dernière partie, nous verrons, à la lumière de ces modèles explicatifs, comment les historiens les plus représentatifs de la période ont abordé la question des Rébellions.

\section{LES MODÈLES EXPLICATIFS DE L'ÉMERGENCE DES NATIONS ET DU NATIONALISME}

Christophe Jaffrelot, dans un article éclairant publié récemment, nous propose un regroupement des modèles théoriques du fait national autour de «trois paradigmes dominants », selon que ces modèles considèrent la nation et le nationalisme comme «donnés» ou comme «construits». Il introduit également la dimension temporelle pour distinguer les théories qui s'inscrivent dans le temps long, des autres qui ne conçoivent le nationalisme «que comme un phénomène de la modernité d'après la Révolution industrielle ${ }^{43} \gg$.

Ces trois paradigmes, qui recouvrent les principaux modèles d'analyse, sont: la modernisation, la permanence des ethnies et, enfin, la diffusion et la construction idéologiques. Nous nous en tiendrons, pour les fins de cet article, au premier paradigme qui lie modernisation et nationalisation parce qu'il est le plus fécond et celui qui a produit les études les plus complètes sur le sujet. Ces dernières ont en commun le fait de valoriser les «processus de modernisation dans l'explication du nationalisme» et d'établir une corrélation entre le change-

43. Christophe Jaffrelot, «Les modèles explicatifs des nations et du nationalisme, revue critique », dans Gil Delannoi et Pierre-André Taguieff, dir., Théories du nationalisme, Nation, nationalité, ethnicité (Paris, Kimé, 1991), 139-140; 173. 
ment social provoqué par les transformations économiques et technologiques de l'ère industrielle et la conscience nationale liée à la modernisation et à l'intégration ${ }^{44}$. Ce premier paradigme s'impose à nous très fortement dans la mesure où l'idée de modernisation occupe une place prépondérante dans l'historiographie récente.

Les auteurs regroupés sous le paradigme de la modernité appartiennent à l'école du Nation Building. Stein Rokkan, Karl Deutsch et Ernest Gellner en sont les représentants les plus connus et ils ont, chacun à leur façon, fait école en développant une variante originale du même modèle.

La variante pérenniale

La première variante dite pérenniale a été élaborée par Stein Rokkan qui a eu recours au temps long pour expliquer la lente émergence de l'État-nation dans 17 pays de l'Europe de l'Ouest. Rokkan construit un modèle complexe articulé autour de quelque 13 variables économiques, territoriales et culturelles dont il retrace l'évolution à travers 4 époques qui vont du Haut Moyen-Âge à la fin du XVIII ${ }^{e}$ siècle. Ces États de l'Europe de l'Ouest entrent alors dans un processus accéléré d'édification de la nation sous l'influence de six nouvelles variables : économiques comme l'industrialisation et l'urbanisation; territoriales comme les mouvements contraires vers la centralisation et l'unification, d'une part, et les aspirations à la libération et à la sécession, d'autre part; culturelles, enfin, comme la mobilisation ethnolinguistique. Cette phase de l'évolution de l'Étatnation va de 1789 aux années $1920^{45}$.

Il résulte de cette enquête la perception d'un cheminement dialectique entre les processus d'industrialisation, d'urbanisation et de sécularisation des sociétés, et l'édification des nations. Ce modèle d'analyse laisserait entrevoir cependant une absence que les recherches de Karl Deutsch, théoricien de la même école, viendront combler. La typologie élaborée par Rokkan fait, en effet, beaucoup de place à l'État aux dépens de la nation ${ }^{46}$ et du «nationalisme», compris ici comme autodétermination des peuples. Un de ses mérites réside dans la relation, pertinente pour notre propos, entre le phénomène de modernité et l'émergence de l'État.

44. Ibid., 140 .

45. Stein Rokkan, «Un modèle géo-économique et géo-politique de quelques sources de variations en Europe de l'Ouest», Communications, 45 (1987); R. L. Merritt et S. Rokkan, dir., Comparing Nations. The Use of Quantitative Data in Cross-National Research (New Haven, Yale University Press, 1966).

46. C. Jaffrelot, loc. cit., 139 et ss. 
La variante cybernétique de Karl Deutsch

Cette recherche d'un modèle conceptuel, qui prendrait en compte la nation et la nationalité plutôt que l'État, décrit bien la démarche suivie par Karl Deutsch qui limite son observation à la période industrielle ou proto-industrielle, donc au temps court. Cette variante est qualifiée de «cybernétique» par un commentateur parce que cet auteur a la conviction que les mouvements nationalistes, tout comme la modernisation liée aux innovations technologiques de l'âge industriel à laquelle elles sont associées, sont des phénomènes observables empiriquement et mesurables quantitativement. «Aborder le problème de façon empirique quantitative, probabiliste et combinatoire», écrivait Deutsch, devrait permettre de rendre compte des traits communs et différents «de la montée des mouvements nationalistes ${ }^{47}$ ». Cette stratégie de recherche comparée, élaborée au début des années 1950, permit à Deutsch de formuler ses trois théories complémentaires et évolutives de la communication sociale, de la mobilisation sociale et de l'intégration politique, pour expliquer «le processus de construction des nations » pendant leur passage de société traditionnelle à société industrielle ${ }^{48}$.

Ces théories l'amènent d'abord à définir le peuple comme un groupe d'individus formant une communauté d'habitudes communicationnelles complémentaires exprimées à travers la culture, la langue, les moyens de communication de masse et à établir une coïncidence entre culture et société, si tant est que la culture «est fondée sur une communauté de communication». Prenant appui sur cette définition fonctionnelle et neutre de la nation, l'auteur affirme que la mobilisation sociale inhérente à la communication augmente en période de modernisation de l'économie, de stratification sociale multiple et de mobilité concurrentielle accrue. Cette mobilisation sociale au sein de chaque communauté culturelle est mesurable et est liée à la communication qui favorise à son tour l'importance du langage, de la culture nationale et ethnique et donc la montée du nationalisme ${ }^{49}$.

Le modèle évolutif proposé par Deutsch situe lui aussi l'apparition de la nation dans la phase plus ou moins longue où elle effectue son passage vers l'industrialisation, alors qu'elle intensifie ses «facultés de communiquer effectivement » par la croissance de l'alphabétisation

47. Karl Deutsch, «Vers une compréhension scientifique du nationalisme et du développement national: l'apport critique de Stein Rokkan», dans G. Delannoi et P.-A. Taguieff, op. cit., 285-288; id., Tides Among Nations (New York, The Free Press, 1979), 297-314.

48. K. Deutsch, «Vers une compréhension... », loc. cit.; C. Jaffrelot, loc. cit., 141-142.

49. K. Deutsch, «Vers une compréhension...», loc. cit., 286. 
et de la communication de masse ${ }^{50}$, deux domaines quantifiables également. La taille d'une nation et sa cohésion, conséquence d'une intense mobilisation sociale, augmentent donc en fonction du «degré d'avancement de la faculté de communiquer» dans une collectivités1. Ce degré se mesure au moyen d'indicateurs comme les taux d'urbanisation, de population active dans les secteurs secondaires et tertiaires, de lecture de la presse, etc. Suivent alors, inévitablement, l'intégration politique des populations sous une culture dominante comme cela s'est produit dans la majorité des pays du monde atlantique. Les États possédaient pour cela deux instruments puissants de communication et d'homogénéisation: l'école et l'armée. Ces deux institutions avaient également l'avantage de développer la conscience nationale et politique, ou comme l'a écrit Benedict Anderson, l'imaginaire national. C'est là un domaine sur lequel Deutsch s'est peu attardé, mais qui a beaucoup intéressé Ernest Gellner dont l'œuvre accorde une place importante à une sociologie des faits de culture et de langue.

De la théorie de Deutsch, outre la pertinence de la modernisation des sociétés qui provoque une extension de la communauté de culture, retenons la place accordée à la communication, donc de la langue, dans la définition de la nation et dans l'éclosion de la mobilisation sociale et de la conscience nationale.

Nous voici donc arrivés à la troisième variante du paradigme Modernisation et nationalisme, mise en valeur par l'anthropologue Ernest Gellner qui aurait conçu, selon plusieurs, le modèle le plus achevé sur la question ${ }^{52}$.

La variante Modernisation et conflits: le modèle Gellner

Comme ses prédécesseurs, le modèle Gellner s'inscrit dans le cadre de la transition des sociétés traditionnelles vers l'industrialisation. L'apparition au XIX ${ }^{\mathrm{e}}$ siècle de phénomènes comme le capitalisme, la révolution industrielle et le nationalisme n'est pas fortuite ou pure coïncidence. Il y aurait des liens de nature dialectique entre «âge du capital» et «âge du nationalisme» qu'il faut expliquer. Pour Gellner, seule la société industrielle pouvait «nourrir le nationalisme ${ }^{53}$ », car il serait en réalité «une conséquence de l'organisation sociale industrielle» dont les effets, comme la mobilisation sociale définie par Deutsh, se confondraient souvent «avec les autres consé-

50. Cité par C. Jaffrelot, loc. cit., 142

51. Cité par C. Jaffrelot, ibid. 43-45.

52. Patrick Cabanel, La question nationale au XIX $X^{e}$ siècle (Paris, La Découverte, 1997),

53. Ibid. 
quences de l'industrialisme ${ }^{54} »$. Pour illustrer ce long cheminement vers cette nouvelle organisation sociale dont l'«homogénéisation culturelle» constitue aussi une composante ${ }^{55}$, Gellner a recours à la fable des Ruritaniens que nous empruntons également pour sa valeur symbolique et suggestive évidente.

Les Ruritaniens formaient une nationalité paysanne et parlaient des dialectes apparentés à ceux des autres Ruritaniens de leur contrée, mais cependant tous différents de la langue parlée par l'élite cultivée de la cour de Mégalomanie (comprendre l'Empire austro-hongrois ou russe). Ces communautés rurales traditionnelles tournées sur ellesmêmes, isolées des autres communautés rurales et éloignées du pouvoir avec lequel elles n'entretenaient que peu ou pas du tout de relations, se reproduisaient donc dans le cadre d'un système social et économique clos qui ne nécessitait qu'une formation spécialisée transmise localement dans l'atelier du maître ou dans le cercle familial ${ }^{56}$. $\mathrm{Au} \mathrm{XIX}^{\mathrm{e}}$ siècle, sous l'effet du nouvel ordre industriel, les Ruritaniens entreprirent leur migration vers les régions industrialisées de Mégalomanie où l'on recherchait des travailleurs qui ne soient "plus enferrés dans leur routine traditionnelle», qui comprennent une autre langue que le patois et qui sachent lire et écrire ${ }^{57}$. Ces Ruritaniens ressentirent alors, pour la première fois, l'humiliation liée à leur spécificité culturelle et ils en prirent subitement conscience.

C'est dans ces circonstances que naquît la nation ruritanienne, phénomène encouragé par les étudiants, les artistes, les intellectuels, les ethnologues, etc., qui commencèrent à valoriser et à réhabiliter leur héritage culturel quand ils n'allèrent pas jusqu'à le «fabriquer ${ }^{58} »$. Ces derniers groupes deviendront par la suite les principaux porte-parole des Ruritaniens et les futurs dirigeants de la République ruritanienne.

De cette fable, Gellner en arrive à déduire «les deux facteurs essentiels qui entreraient dans la constitution de la société moderne», c'est-à-dire le pouvoir et l'éducation (la haute culture), auxquels il ajoute l'«identité de culture». La combinaison de ces facteurs lui permet d'établir ensuite les huit situations conflictuelles typiques, sociales ou socio-ethniques, qui adviendraient en même temps que la société moderne ${ }^{59}$. Cette dimension conflictuelle du modèle Gellner confère toute son originalité à la variante Modernisation et nationa-

\footnotetext{
54. E. Gellner, op. cit., 63-67 et 78 .

55. Ibid.

56. Ibid., chap. 4.

57. Ibid., 67; G. Hermet, op. cit., 68-69.

58. E. Gellner, op. cit., 86-87.

59. Ibid., 129 et ss.
} 
lisme de l'école du Nation building. Elle est connue d'ailleurs sous l'étiquette Modernisation et conflits. De ces huit possibilités produites par son analyse, Gellner ne retient que trois situations où il y a différenciation culturelle et sur lesquelles, par conséquent, le nationalisme a prise. L'une d'elles, qu'on retrouve dans le nationalisme de diaspora, celui des Juifs par exemple, est tout à fait exceptionnelle. Elle ne s'identifie pas à un territoire. Restent donc deux formes typiques de nationalisme où deux cultures cohabitent sur un même territoire et où l'une d'elles détient le pouvoir et l'autre pas. Il s'agit du «nationalisme de type "Habsbourg" et du "nationalisme libéral occidental classique" ${ }^{\prime \prime} »$. C'est aussi le cas canadien.

Le nationalisme du type Habsbourg nous renvoie aux petits peuples sans histoire dont la majorité vivent sous la domination des empires centraux. Là, les détenteurs du pouvoir ont également «un accès privilégié à une haute culture centrale [littéraire et technologique] qui est, en fait, la leur, et à toutes les ficelles qui font qu'un homme s'en sort bien dans un contexte moderne». Parmi eux se retrouvent souvent aussi les propriétaires fonciers, les capitalistes et les bureaucrates ${ }^{61}$. Les autres, qui n'ont accès ni au pouvoir ni à une haute culture, ont cependant en commun une culture populaire que des intellectuels «à force de ténacité et de propagande soutenue et normalisée » essaient de «transformer en une nouvelle haute culture rivale». Quand les conditions sont propices, c'est-à-dire quand l'oppression de la masse populaire par une nation de langue et de culture étrangères devient visible et intolérable, «ce groupe se donne un État qui entretient et protège cette culture qui vient de naître ou de renaître».

Dans l'autre situation, appelée par Gellner «nationalisme libéral occidental classique», certains ont le pouvoir, d'autres pas. Ce qui distingue les premiers des seconds, c'est leur appartenance à une culture différente. Quant à l'accès à l'éducation, il n'y a «aucune différence significative entre les populations concernées ${ }^{62} »$. Cette situation correspond à la réalité historique de l'Italie et de l'Allemagne. L'infériorité culturelle des populations italiennes et allemandes était, en effet, presque nulle. Italiens et Allemands s'exprimaient dans une langue normalisée et disposaient d'institutions, académies et universités capables de produire une haute culture littéraire et scientifique. Mais les Italiens dans leur majorité étaient gouvernés par des puissances étrangères et les Allemands dans leur ensemble vivaient dans des petits États morcelés en regard des grandes puissances européennes

60. Ibid., 141 et ss.

61. O. Bauer, op. cit., 1: 198

62. E. Gellner, op. cit., 143. 
comme la France et l'Angleterre. Il leur manquait un toit politique pour protéger cette culture bien développée.

Ce dernier type de nationalisme qui recherche l'unification au nom d'une haute culture est très attaché, comme nous l'avons vu en première partie, aux idées libérales, et est aussi l'expression politique d'une intégration économique voulue par les bourgeoisies prussienne et piémontaise. Cette motivation de nature économique ne semble pas avoir joué un rôle significatif dans l'autre nationalisme, qualifié parfois d'oriental ${ }^{63}$, qui grandit au nom d'une haute culture en formation et dans un climat de rivalité avec d'autres cultures voisines.

La typologie de Gellner s'articule autour des notions de pouvoir, d'éducation et de culture dont la jouissance en période de transition constitue l'enjeu de toutes les aspirations nationales et nationalitaires. Elle rend compte de l'expérience canadienne qui, par certains côtés, se compare au «nationalisme libéral classique», en particulier à l'Italie où, comme au Canada, les détenteurs du pouvoir se distinguaient généralement de la très grande majorité de la population qui en était privée, du fait de leur appartenance à une culture différente.

Nous ne saurions clore cette partie sur les modèles sans évoquer l'œuvre originale de l'historien et politologue tchèque Miroslav Hroch $^{64}$ qui limita justement son analyse au réveil des «petites nations sans histoire» comme la Norvège, la Bohème, la Slovaquie, la Finlande, l'Estonie, la Lituanie, etc. Hroch appartient à la variante $\mathrm{Mo}$ dernisation et conflits dont Ernest Gellner et Karl Deustch sont les principaux représentants.

«Les petites nations sans histoire» et le modèle Miroslav Hroch

Hroch a donc entrepris de définir les critères de comparaison qui lui permettraient d'expliquer la renaissance des petites nations. Ces critères proviennent du profil social des patriotes, considérés à l'intérieur d'un réseau objectif de relations propres à une structure de classes d'une société en voie de transition vers le capitalisme ${ }^{65}$ comme c'est le cas dans les pays pris en compte. Structure de classe bourgeoise donc, à trois niveaux, qu'il appelle l'«intelligentsia» et qu'il décrit ainsi.

63. John Plamnatz, «Two Types of Nationalism», dans E. Kamenka, dir., Nationalism, the Nature and Evolution of an Idea (Londres, 1973). Cité par Gellner, op. cit.

64. Miroslav Hroch, Social Preconditions of National Revival in Europe. A Comparative Analysis of the Social Composition of Patriotic Groups Among the Smaller European Nations (Cambridge, Cambridge University Press, 1985).

65. Ibid., 13, 15 . 
Le premier niveau est composé par les hauts fonctionnaires et les dignitaires ecclésiastiques associés au pouvoir, par les chefs d'entreprises («managers of the big estates») et par l'élite des professions libérales, en particulier des avocats; le deuxième niveau comprend les membres de l'intelligentsia non directement proches du pouvoir comme les avocats, les médecins, les artistes, les journalistes et les scientifiques; le troisième niveau, enfin, concerne ceux qui sont en relations constantes avec le peuple, comme les petits et moyens fonctionnaires, les employés d'entreprises privées et publiques et les instituteurs $^{66}$. L'examen de cette structure de classe bourgeoise permettra à Hroch d'identifier les cinq indicateurs qui lui serviront de base à l'analyse combinatoire, soit: l'occupation, l'origine sociale, le lieu de l'activité patriotique, le lieu de naissance et la formation des individus ${ }^{67}$.

Par cette recherche, Hroch a pu établir les trois phases successives de tout mouvement d'affirmation nationale et décrire le rôle des patriotes dont il avait précédemment esquissé le profil, à l'intérieur de cette séquence temporelle. Séquence qui correspondrait vraisemblablement aux phénomènes de communication et de mobilisation sociales et d'intégration politique qui caractérisent les théories de Deutsch. La première phase $\mathrm{A}$, dite culturelle, correspond en effet à la période de prise de conscience d'une identité collective et de l'intérêt avant tout érudit qu'une certaine élite - l'intelligentsia de deuxième niveau - porte à la langue, à l'histoire, aux traditions, au folklore et à la naissance d'une littérature nationale. Suivent la politisation de la question culturelle par les activistes et les patriotes à l'intérieur d'institutions politiques officielles (phase B) et le mouvement de masse révolutionnaire (phase C) en faveur de l'autodétermination. Pour Hroch, la phase d'agitation patriotique et de politisation de la question identitaire est la plus importante. C'est celle qui se prête le mieux à la comparaison. Cette phase $\mathrm{B}$ de mobilisation sociale et politique occupe donc une place centrale dans son analyse parce que c'est là où, écrit-il, nous pouvons trouver un ensemble de situations historiques ( $a$ set of historical situations) à la fois analogues et comparables ${ }^{68}$.

La pertinence d'une telle approche comparée s'impose. L'essentiel du débat historiographique sur les rébellions de 1837-1838 au Canada ne porte-t-il pas aussi sur cette phase B du mouvement natio-

66. Ibid., 16.

67. Ibid., 14-18. Cette analyse serait réalisable au Canada grâce à la compilation de données semblables. Voir J.-P. Bernard, Les Rébellions de 1837-1838. Les patriotes du BasCanada..., op. cit., chap. 6, «2100 noms de Patriotes avec leur profession et leur âge».

68. M. Hroch, op. cit., 23. 
nal pendant laquelle le Parti canadien, puis patriote, se mobilisait, propageait son idéologie et organisait la rébellion grâce à une structure organisationnelle moderne qui en fit, selon Robert Boily, un véritable parti de masse ${ }^{69}$ ? La mise en perspective suggérée par Hroch viendrait enrichir, sous ce chapitre, un débat qui, depuis quelques années, n'apporte pas suffisamment de nouveaux éléments de réflexion.

Quelles conclusions Miroslav Hroch a-t-il pu tirer de cette analyse comparative? Nous en retenons trois que nous présentons sous forme de corrélations établies, entre mouvements nationaux et origine sociale des patriotes; entre mouvements nationaux et situation financière des patriotes; enfin, entre la structure économique régionale et l'activité patriotique $^{70}$. Concrètement, Hroch a observé, dans tous les cas étudiés, une coïncidence forte entre le facteur urbain et la réussite du mouvement d'émancipation. En clair, cela signifiait que l'agitation patriotique et la mobilisation (phase B) étaient d'autant plus précoces que les patriotes provenaient des milieux urbains comme ce fut le cas en Bohème et en Norvège.

Il semble également que ni la noblesse terrienne ni la bourgeoisie proche du pouvoir (à l'exception de la Norvège) n'aient joué un rôle décisif dans cette même phase d'agitation patriotique. C'était plutôt la catégorie sociale au-dessous des très riches et au-dessus des pauvres qui participa effectivement au mouvement national. "The poorer of the rich, and the richer of the poor ${ }^{71}$.» Cette activite patriotique, enfin, a eu tendance à se manifester dans des régions de production artisanale et d'agriculture prospère qui écoulaient leur production sur le marché local. Tout cela n'est pas sans ressemblance avec le cas canadien où l'agitation patriotique a eu tendance également à se manifester dans des régions agricoles prospères comme la plaine de Montréal et la vallée du Richelieu.

Il nous reste donc maintenant à déduire à notre tour, de toutes ces analyses, les dénominateurs qui leur sont communs comme, dans le cas que nous venons de voir, le rôle joué par la petite bourgeoisie des professions libérales.

69. Robert Boily, «Les partis politiques québécois : perspectives historiques », dans Vincent Lemieux, dir., Personnel et partis politiques au Québec (Montréal, Boréal Express, 1982), 27-68.

70. M. Hroch, op. cit., 156-175.

71. Ibid., 161. 
LES ÉLÉMENTS DE CONVERGENCE PROPRES

AUX EXPÉRIENCES NATIONALES DU XIX ET LEUR TRAITEMENT DANS L'HISTORIOGRAPHIE QUÉBÉCOISE ET CANADIENNE RÉCENTE

À ce stade-ci de notre réflexion, nous pouvons esquisser un bilan provisoire de notre démarche en le présentant sous forme de trois associations principales que nous appelons aussi les trois éléments de convergence consensuels que nous déduisons de ce qui précède et que nous retrouverions généralement dans tout mouvement d'émancipation nationale. Ces éléments, qui tiennent compte à la fois du contexte historique et de l'approche théorique, établissent une relation positive entre, 1) conscience nationale, aspiration à la souveraineté, d'une part, et modernisation et transition, d'autre part;2) entre courant libéral et courant national; et 3) entre émancipation des peuples et rôle mobilisateur déterminant des classes moyennes.

Ces éléments de convergence nous serviront de guide dans la poursuite de l'examen de l'historiographie qui sera l'objet de cette dernière partie. Nous les examinerons chez certains historiens qui ont abordé les rébellions par le biais de la synthèse d'histoire générale comme John Dickinson et Brian Young, Stanley Ryerson et Susan Trofimenkoff; chez certains spécialistes de la période qui ont étudié indirectement les rébellions comme Gilles Paquet et Jean-Pierre Wallot et, enfin, chez certains autres qui ont étudié la période révolutionnaire elle-même comme Fernand Ouellet, Allan Greer, Gérald Bernier et Daniel Salée ainsi qu'Elinor Kyte Senior.

Conscience nationale, modernisation et transition

Depuis une trentaine d'années, les historiens québécois et canadiens ont souvent considéré l'idée de modernité dans leurs interprétations; toutefois, ceux qui ont étudié la période qui nous intéresse l'ont rarement fait dans la perspective proposée par les théoriciens de la question nationale. Aussi n'ont-ils pas suffisamment mis en évidence les relations qui s'imposaient, selon nous, entre certains phénomènes et événements historiques liés aux rébellions. Ainsi, en proposant ou en adoptant, au départ, une interprétation générale de l'histoire du Québec fondée sur l'idée de modernité et de normalité, plusieurs analyses présentent le Québec comme une société moderne, normale, libérale, dont la croissance économique liée à l'industrialisation urbaine serait comparable au développement économique qu'ont connu les autres sociétés occidentales. Cette interprétation vise mani- 
festement à faire contrepoids à la problématique nationaliste ${ }^{72}$ qui serait incompatible avec l'idée de modernité et aurait, pense-t-on, trop souvent déterminé les interprétations et les choix de périodisation ${ }^{73}$.

Il faudrait, selon nous, réexaminer cette approche, dans la mesure où elle a ignoré tout simplement les conséquences politiques du phénomène de la modernisation, introduisant ainsi une première distorsion dans l'interprétation de ce phénomène. Par un choix délibéré, ce type d'analyse relèguerait ainsi la sphère politique à un simple rang contextuel, comme si le politique n'avait pas lui aussi un rôle important dans le développement de la modernité. Ce genre d'interprétation coöncide d'ailleurs avec l'isolement dans lequel a été tenue l'histoire politique depuis la fin des années $1960^{74}$. «[Notre] option, écrivaient John Dickinson et Brian Young dans l'introduction de leur Brève histoire socio-économique du Québec, impliquait des choix idéologiques. La propriété et autres manifestations du pouvoir économique, le droit, les structures sociales, les institutions et les rapports sociaux entre les sexes sont au cœur de notre ouvrage et prédominent sur la politique, la culture et les idéologies, dont le nationalisme ${ }^{75}$.»

Conformément à ses «choix idéologiques», ce courant adopta logiquement une périodisation qui suivait une séquence largement répandue en histoire économique et qui minimisait, par conséquent, les repères politiques conventionnels, comme la conquête anglaise de 1760, les rébellions de 1837 et de 1838 et la Confédération de 1867. «Les gens de ma génération, affirmait Paul-André Linteau ${ }^{76}$, coauteur d'une Histoire du Québec contemporain, se sont beaucoup préoccupés d'étudier les structures; leur histoire a fait une large place aux grands schémas d'interprétation, aux perspectives théoriques. » Ce point de vue pertinent nous intéresse dans la mesure où il a inspiré le commentaire suivant à Ronald Rudin, qui en parlant de cette catégorie d'historiens, affirme: «C'est tout à [leur] honneur [...] [d'avoir] essayé de laisser de côté la question nationale dans leur récit du développement économique et social, justement parce qu'ils inscrivaient le Québec dans un contexte international plus large ${ }^{77}$.» Commentaire surprenant

72. Gérard Bouchard, «L"'habitant canadien-français", version saguenayenne : un caillou dans l'identité québécoise», Bulletin d'histoire politique, 5,3 (été 1997): 21.

73. J. A. Dickinson et B. Young, op.cit., 10.

74. Réal Bélanger, «Pour un retour à l'histoire politique», Revue d'histoire de l'Amérique française, 51,2 (automne 1997): 223-241.

75. J. A. Dickinson et B. Young, op. cit., 10.

76. Paul-André Linteau, «La nouvelle histoire du Québec vue de l'intérieur », Liberté, 35 (1983): 46.

77. Ronald Rudin, «La quête d'une société normale: critique de la réinterprétation de l'Histoire du Québec», Bulletin d'histoire politique, 3,2 (1995) : 12-13. 
et réducteur qui confinerait la question nationale québécoise à la marginalité, alors que la question nationale en général serait, selon une analyse récente sur le sujet, «la principale clé de lecture de l'histoire géopolitique européenne au XIX ${ }^{\mathrm{e}}$ siècle $^{78}$ ».

Est-ce pur hasard si la période de transition vers le capitalisme industriel canadien est justement la même période pendant laquelle couve la révolte sous Craig (1807-1811), éclate la rébellion de 1837 et se construit graduellement l'intégration politique et économique des colonies britanniques de l'Amérique du Nord? Phénomènes et événements qui renvoient plus ou moins, selon les cas, au pattern suivi par les nations européennes notamment? Cette simultanéité dans le temps serait-elle pure coïncidence? La constitution des États ne se présentet-elle pas, elle aussi, comme la solution politique aux problèmes d'intégration des économies nationales comme l'ont si bien montré, entre autres, Eric Hobsbawm ${ }^{79}$, Charles Morazé ${ }^{80}$ et Sidney Pollard ${ }^{81}$ pour l'Europe et Stanley Ryerson, Alfred Dubuc et Jean-Pierre Wallot pour le Canada.

Cette «inscription du Québec dans un contexte international plus large », souhaitée par plusieurs, aurait pu permettre de pousser plus loin la réflexion moderniste mettant alors en évidence cette autre normalité, politique cette fois, qu'est l'émergence de l'État-nation et de la nationalité un peu partout en Occident. C'est justement à ce type de questionnement et de problématique que nous convient des modèles d'analyse comme ceux de Rokkan, Deutsch, Gellner et Hroch.

Cette volonté d'inscrire le Québec dans la normalité libérale, tout en refusant de poser la question nationale québécoise dans la perspective moderne de l'émergence de l'État-nation qui lui est contemporain, ne créerait-elle pas une nouvelle «anormalité », caractérisée cette fois par la dissociation de ce qui a été pourtant fortement associé dans l'histoire des nations, soit le phénomène de la transition et l'avènement des nations? L' «âge du capital» et l' «âge des nations », comme le courant libéral et national qui les porte souvent, ont eu tendance à se confondre tant les liens qui les unissaient étaient forts. Stanley Ryerson $^{82}$ et le sociologue Gilles Bourque ${ }^{83}$, conformément à l'appro-

\footnotetext{
78. P. Cabanel, op. cit., 3-4. 121-142.

79. Eric Hobsbawm, «L'édification des nations », L'ère du capital (Paris, Fayard, 1978),

80. Charles Morazé, «Les nationalismes industriels», Les bourgeois conquérants, $19^{e}$ siècle (Paris, A. Colin, 1957), 233-264.

81. Sidney Pollard, The Integration of European Economy Since 1815 (London, George Allen \& Unwin Ltd, 1981), 27-41.

82. Stanley B. Ryerson, Le capitalisme et la confédération (Montréal, Parti Pris, 1972).

83. Gilles Bourque, Question nationale et classes sociales au Québec (1760-1840) (Montréal, Parti Pris, 1970).
} 
che marxiste, l'ont affirmé, il y a déjà longtemps, sans toutefois approfondir suffisamment la question.

Jean-Pierre Wallot et Gilles Paquet ${ }^{84}$ dans «Groupes sociaux et pouvoir: le cas canadien au tournant du $\mathrm{XIX}^{\mathrm{e}}$ siècle» et, plus récemment, dans Le Bas-Canada au tournant du $19^{e}$ siècle [...], inscrivent eux aussi le Bas-Canada dans la modernité en établissant, bien à propos, la corrélation entre transition au Bas-Canada («grande discontinuité ») et l' «affirmation sociale et nationale», non pas des Canadiens cependant, mais des Canadiens français ${ }^{85}$. Ethniques plutôt que nationalitaires, en effet, leur sont apparus les conflits qui opposaient «Britanniques et Canadiens » sitôt après l'instauration du régime parlementaire ${ }^{86}$. «L'aspect ethnique ou national [aurait même] fait achopper toute possibilité de révolution bourgeoise.» Nuance importante qui vient réduire aussitôt la portée de «l'affirmation nationale» et laisse supposer que, sans dissocier en théorie, modernisation et aspiration nationale, ils l'excluent, en pratique, dans leur perception de la situation objective. Ils n'ont pas retenu que l'ethnicité, comme l'ont démontré, entre autres Gellner, Bauer, Croce, fut un facteur déterminant de l'émergence des États-nations. Au contraire, pensent-ils, elle «finira, après 1820, par paralyser toute la société canadienne», rendant finalement toute révolution bourgeoise impossible, «sauf sur le plan national ${ }^{87} \gg$. Nous voilà donc replongés en pleine dissociation entre révolution bourgeoise et révolution nationale.

Plus près de nous, deux politologues, Gérald Bernier et Daniel Salée ${ }^{88}$, ont placé résolument l'idée de transition au centre de leur interprétation des rébellions. «La notion de transition, écrivent-ils, fait ressortir l'existence d'une conjoncture sociopolitique complexe et conflictuelle qui n'est pas étrangère aux troubles des années 1830 $[\ldots]^{89}$.» Les événements de 1837-1838 seraient ainsi à la fois «une lutte de libération nationale», la «manifestation de la transition vers le capitalisme et vers l'établissement d'un système de démocratie libérale» et «une attaque de plein fouet contre des institutions [...] d'Ancien Régime ${ }^{90} »$. La problématique énoncée par ces deux auteurs s'inscrit très bien dans la perspective moderniste. Elle rejoint aussi

84. J.-P. Wallot et G. Paquet, «Groupes sociaux...», loc. cit. ; id., Le Bas-Canada au tournant du $19^{e}$ siècle : restructuration et modernisation (Ottawa, Société historique du Canada, brochure historique, $\mathrm{n}^{\circ} 45,1988$ ).

85. G. Paquet et J.-P. Wallot, Le Bas-Canada..., op. cit., 3, 5, 9.

86. Ibid., 12-13.

87. J.-P. Wallot, «Révolution et réformisme...», loc. cit., 431-434.

88. G. Bernier et D. Salée, op. cit.

89. Ibid., 176.

90. Ibid., 173-174. 
parfaitement les modèles élaborés par les théoriciens de la nation qu'on regroupe généralement sous le paradigme Modernisation et nationalisme. Malheureusement, ces modèles, qui font une large place à l'approche comparative, ne les ont pas touchés. Pourtant, ils leur auraient permis de dégager une problématique neuve sur la dynamique interne de la question nationale.

On se rend donc compte que l'approche de certains historiens, identifiés au courant moderniste récent, représente un net recul par rapport à l'ouvrage stimulant de Bernier et Salée, de celui de Paquet et Wallot et, surtout, par rapport à l'Histoire économique et sociale du Québec, 1760-1850 de Fernand Ouellet, publié en 1966, dont le soustitre référentiel aux structures et conjoncture précise bien la perspective globale qui guida l'auteur. Chez Ouellet, comme chez Bernier et Salée et chez Paquet et Wallot, les deux trames économiques et politiques ne s'excluent pas l'une l'autre, même si leurs interprétations à d'autres niveaux diffèrent. On pourrait même en déduire, dans le passage suivant de Fernand Ouellet, les éléments de modernité et de conflits, propres aux modèles d'un Rokkan, d'un Gellner ou d'un Hroch :

Il nous paraît évident qui si le mouvement insurrectionnel n'avait eu que des racines politiques, même lointaines, il n'aurait pas eu lieu. [...] Comme nous croyons l'avoir démontré, la crise qui prépare l'explosion insurrectionnelle était d'abord économique et sociale avant d'être politique. La crise agricole, les tensions démographiques et sociales, la situation particulièrement critique des professions libérales sont les fondements principaux de la réaction nationaliste ${ }^{91}$.

Pourtant Ouellet s'éloigne des modèles évoqués plus haut quand il conclut à la réaction nationaliste - ce qui est un anachronisme là où il aurait dû voir une réaction «nationalitaire». Ouellet se refuse, en effet, à voir dans les insurrections de 1837 une guerre d'émancipation nationale. Ces dernières, alimentées par la crise agricole, n'auraient été qu'un prétexte utilisé par la petite et moyenne bourgeoisie des professions libérales pour accéder au leadership d'une société ultraconservatrice ${ }^{92}$.

91. F. Ouellet, Histoire économique..., op. cit., 414.

92. F. Ouellet, «Les insurrections de 1837-1838: un phénomène social», dans J.-P. Bernard, Les rébellions de 1837-1838. Les patriotes du Bas-Canada... , op. cit., 221-222. 
Courant libéral - courant national

Cette interprétation instrumentaliste du rôle des élites vient accréditer la thèse du nationalisme «conservateur» des patriotes. Thèse reprise chez bon nombre d'historiens qui ont réduit par la suite la question nationale aux rapports plus ou moins conflictuels et «chauvins » entre Anglais et Canadiens. C'est la perspective qu'a privilégiée Elinor Kyte Senior dans Redcoats and Patriotes ${ }^{93}$ publié en 1985 et qui représente un exemple parfait d'une histoire qui refuse de pousser l'analyse assez loin. Une analyse qui aurait pu souligner le fait que l'échec de l'objectif nationalitaire des Canadiens en 1837 et, par là, leur mise en minorité sous l'Union, ont provoqué une redéfinition effectivement conservatrice du nationalisme canadien chez les réformistes de LaFontaine, les libéraux-conservateurs de Cartier et chez les élites cléricales. Cette redéfinition, centrée désormais sur l'idée de survivance canadienne-française, a eu pour effet, sur le plan du discours, de «détacher le nationalisme de son contenu libéral », le vidant de son objectif politique, au profit d'un objectif culturel à caractère religieux ${ }^{94}$.

Une telle dissociation entre pensée libérale et mouvement national, déjà dénoncée dès 1844-1845 par certains libéraux autour de Papineau et de Dessaulles ${ }^{95}$, fut vite intégrée dans le nouveau discours nationaliste par les idéologues ultramontains et leurs alliés politiques qui en assurèrent la diffusion jusqu'à nos jours. Cela expliquerait peutêtre la confusion qui entoure encore ces deux notions dans notre historiographie, malgré les recherches de Nadia F. Eid qui montrent bien par quel cheminement idéologique les valeurs nationales ont rejoint, pour un temps donné et à la faveur d'une conjoncture précise, le champ des principes conservateurs et celles d'un Stanley Ryerson et d'un Jean-Pierre Wallot qui lient effectivement courant libéral et question nationale. Wallot parle justement «de mariage de ces deux courants $^{96} »$. Il faudrait souligner aussi le Dessaulles d'Yvan Lamonde où ce dernier rend compte du triplet libéralisme, nationalisme et mouvement nationalitaire qui est au cœur de la pensée libérale qui survécut à travers L'Avenir, l'Institut canadien ${ }^{97}$ et certains libéraux marginaux

93. Elinor Kyte Senior, Redcoats and Patriotes (Ottawa, Canada's, Wings Inc, 1985); la traduction française est parue chez vlb éditeur en 1997, sous le titre: Les habits rouges et les patriotes.

94. Nadia F. Eid, Le clergé et le pouvoir politique au Québec, une analyse de l'idéologie ultramontaine au milieu du XIX siècle (Montréal, Hurtubise HMH, 1978), 249.

95. Yvan Lamonde, Louis-Antoine Dessaulles, 1818-1895. Un seigneur libéral et anticlérical (Saint-Laurent, Fides, 1994), 56 et ss.

96. J.-P. Wallot, «Révolution et réformisme...», loc. cit., 393.

97. Y. Lamonde, Louis-Antoine Dessaulles..., op. cit. 
et méconnus comme Éva Circé-Côté dont le Papineau, publié en 1924 , se voulait en fait une tentative de réhabilitation du «véritable libéralisme ${ }^{98} \gg$.

L'influence cléricale-conservatrice dominante, qui contribua au milieu du $\mathrm{XIX}^{\mathrm{e}}$ siècle à dissocier la pensée libérale et la pensée nationale, se perçoit encore dans des travaux récents. Dans les pages de leur Brève histoire socio-économique du Québec qu'ils consacrent aux rébellions, John Dickinson et Brian Young associent dès l'introduction l'échec des «rébellions de 1837-1838» à «la défaite du nationalisme conservateur» et écrivent au sujet de Papineau et de ses «collègues » que leurs «ambiguïtés sur les objectifs sociaux, religieux et nationaux firent de la première rébellion de 1837 un mouvement aux objectifs sociaux essentiellement conservateurs et nationalistes ${ }^{99} »$. Dans sa présentation de textes choisis de Papineau, Ouellet exprime encore plus clairement cette même opposition: «Si les positions libérales et démocratiques [des patriotes] paraissent dominantes, elles ne réussissent pas à masquer des attitudes nationalistes inconciliables avec un sain libéralisme ${ }^{100}$.» Pour Susan Trofimenkoff, auteure elle aussi d'une synthèse d'histoire du Québec, l'association libérale et nationale n'est que stratégie politique momentanée. Elle ne serait après tout qu' «un langage en vogue » récupéré par l'élite des classes moyennes qui aspirait à prendre le contrôle du patronage et à occuper les places des Anglais en «revêt[ant] ses ambitions politiques du manteau du nationalisme ${ }^{101} »$.

C'est ici que l'approche comparative s'avérerait éclairante pour évaluer des interprétations trop rapides et qui vont à contre-courant des interprétations récentes de l'historiographie européenne en particulier, à savoir que la lutte pour la démocratie, la prise de conscience de l'identité et le désir d'unité culturelle dans l'État-nation sont, comme l'écrit Isaiah Berlin, "parmi les postulats admis par les penseurs rationalistes de tendance libérale ${ }^{102} \gg$. En effet, si nous avons bien lu les historiens qui se sont penchés sur ces questions en Europe, non seulement les positions libérales et nationales apparaissent intimement liées au point où il fut difficile parfois de les distinguer ${ }^{103}$, mais

98. Éva Circé-Côté, Papineau. Son influence sur la pensée canadienne. Essai de psychologie historique (Montréal, R. A. Regnault \& Cie, imprimeurs, 1924).

99. J. A. Dickinson et B. Young, op. cit., 12, 186.

100. F. Ouellet, dir., Papineau, op. cit., 47.

101. Susan Mann Trofimenkoff, Visions nationales, une histoire du Québec (Montréal, Trécarré, 1986), 77, 86.

102. I. Berlin, loc. cit., 367.

103. N. Rousselier, op. cit., 32-33. 
elles se retrouvent aussi «clairement à gauche ${ }^{104} »$. Comme dirait encore l'historien Rousselier, «le courant libéral [...] devient le principal vecteur de l'unité nationale ou de l'unification à réaliser ${ }^{105} »$. Une mise en perspective serait donc nécessaire pour expliquer le conservatisme atypique des patriotes canadiens chez beaucoup d'historiens.

Pour cela, il serait utile de clarifier d'abord certains concepts qui ont pris ici des connotations anachroniques. Nous pensons à «nationalisme» et «nationaliste» qui, comme l'a montré Hobsbawm, entre autres, sont des mots nouveaux qui n'apparaissent dans les dictionnaires que tardivement dans le siècle, au moment où les rivalités entre États firent apparaître des attitudes belliqueuses et égocentriques. Avant 1850, comme l'a écrit si justement Fernand Dumont: «le nationalisme n'était encore ni une mentalité bien caractéristique, ni un état d'esprit bien déterminé, encore moins une doctrine politique ${ }^{106}$. » L'utilisation du terme «nationaliste» nous renvoie nécessairement à l'idée d'autodétermination des peuples. Le libéralisme dans le contexte des rébellions de 1837 ne pouvait être nationaliste au sens péjoratif qu'a revêtu ce terme plus tard; il était plutôt nationalitaire, dans ce sens qu'il était un instrument de lutte contre toutes les contraintes, surtout contre celles de la domination étrangère. On retrouve cette compréhension des choses dans le Papineau d'Éva Circé-Côté quand elle parle du «vent de libéralisme» qui «se mit à souffler dans les esprits » et dans les «petites gazettes [...] qui essaimaient partout les principes libertaires ${ }^{107} »$. On le retrouve aussi plus près de nous chez les Bernier et Salée quand ils écrivent au sujet des patriotes, qu'ils "préconisaient un projet de société différent, reposant sur une souveraineté politique absolue, sur l'abolition des structures sociales, économiques et politiques de l'Ancien Régime et sur l'établissement d'une démocratie libérale ${ }^{108}$.»

Ne faut-il pas reconnaître là aussi la lutte pour les «libertés libérales» qu'a si bien analysée l'historien italien Benedetto Croce? Venons-en maintenant à notre dernier point, au rôle de l'intelligentsia dans la rébellion.

104. P. Cabanel, op. cit., 57.

105. N. Rousselier, op. cit., 62-63.

106. Fernand Dumont, Genèse de la société québécoise (Montréal, Boréal, 1993), 373.

107. É. Circé-Côté, op. cit., 85-87.

108. G. Bernier et D. Salée, op. cit., 171-172, 
Le rôle des classes moyennes dans les rébellions et la participation des masses

Tant dans les synthèses de l'histoire de l'Europe au XIX ${ }^{\mathrm{e}}$ siècle que dans les modèles explicatifs de l'émergence des nations et des nationalités, un point de convergence s'impose fortement et fait consensus : c'est le rôle primordial qu'ont joué partout les classes moyennes. Au Canada, cette évidence n'a pas échappé aux principaux historiens de la période, même si leurs interprétations diffèrent des modèles évoqués sur le plan de la dimension nationale du mouvement et sur celui des motivations réelles des patriotes. Objectivement cependant, le récit qu'ils font des événements cadre bien avec le modèle développé par Miroslav Hroch pour les petites nations. Retenons de Hroch deux éléments importants: sa description de la bourgeoisie, ou de ce qu'il appelle l'«intelligentsia», et la trame séquentielle par laquelle passeraient tous les mouvements d'émancipation nationale dans les pays pris en compte; trame qui va de la phase A de la prise de conscience nationale à la révolte des masses en phase $\mathrm{C}$.

Comme l'intelligentsia décrite par Hroch (tableau), la structure de classes au Canada présente un profil pyramidal à peu près identique. En haut de la structure, on retrouve les hauts fonctionnaires et les officiers supérieurs (gentilité bureaucratique et militaire), la bourgeoisie d'affaires et l'élite des professions libérales comme les juges, qui sont en majorité britanniques ${ }^{110}$ et qui appartiennent à la catégorie des «grands propriétaires fonciers ${ }^{111}$ ». Comme l'écrit à ce propos Donald Creighton, «[...] the civil service was largely monopolized by Englishmen who came out to make careers for themselves in the colonies $^{112}$ ». Sont associés à ces gens de pouvoir ou près du pouvoir, comme partenaires du "pacte aristocratique», le haut clergé et les seigneurs canadiens qui se sentent menacés par les membres de la moyenne et petite bourgeoisie des professions libérales qui aspirent au leadership social grâce à leur participation à la vie parlementaire ${ }^{113}$. Ces derniers, que Hroch situerait au niveau moyen de sa structure de classes, comprennent des avocats, des médecins, des journalistes et aussi des marchands. Viennent enfin ceux qui vivent auprès du peuple comme le notaire, le curé, le petit marchand, l'instituteur. Comme dans l'exemple des «petites nations sans histoire», les patriotes se

110. F. Ouellet, «Les insurrections...», loc. cit., 219 et ss; S. Ryerson, op. cit., 241;

G. Paquet et J.-P. Wallot, Le Bas-Canada..., op. cit., 8-9.

111. G. Bernier et D. Salée, op. cit., 139 et ss.

112. D. Creighton, op. cit., 214

113. F. Ouellet, «Les insurrections... », loc. cit., 220 et ss; G. Bernier et D. Salée, op. cit., 71-72 et 174-175. 
TABLEAU

STRUCTURE DE CLASSES COMPARÉE DES PETITES NATIONS ET AU BAS-CANADA*

\section{PETITES NATIONS}

«Class structure of the traditional society»

1. Élites associées au pouvoir

Hauts fonctionnaires

Dignitaires religieux

«Managers of big estates»

Élites des professions libérales

2. Professionnels non associés au pouvoir ou à la grande entreprise

Avocats, médecins, etc.

3. Petits fonctionnaires

Commis, bas-clargé, instituteurs

\section{BAS-CANADA}

Structure de classes au Bas-Canada

1. Élites associées au pouvoir

Hauts fonctionnaires (gentilité bureaucratique en militaire)

Dignitaires religieux (pacte aristocratique)

Officiers

Bourgeoisie d'affaires

Élites des professions libérales Les seigneurs (pacte aristocratique)

2. Professionnels non associés au pouvoir ou à la grande entreprise

Moyenne et petite bougeoisie

\section{Petits fonctionnaires}

\section{Le peuple}

Classes populaires, urbaines et rurales

* Tableau inspiré de M. Hroch, op. cit., de G. Paquet et J.-P. Wallot, «Groupes sociaux...», loc. cit., et id., Le Bas-Canada..., op. cit. 
retrouvent principalement aux niveaux inférieurs de cette structure et sont eux aussi à l'exception de Papineau peut-être «the poorer of the rich, and the richer of the poor ${ }^{114} »$. Pour Paquet et Wallot, ils sont les «exclus du pouvoir», contrairement à la «gentilité » à très grande majorité britannique qui «domine le pouvoir exécutif ${ }^{115}$ ».

On remarque ces petits bourgeois dans les trois phases du mouvement d'affirmation nationale, depuis l'émergence de l'identité nationale et la prise de conscience politique ${ }^{116}$ (phase A) en passant par la période des revendications politiques à l'intérieur des institutions parlementaires d'abord (phase B), pour finir par l'encadrement et la mobilisation des masses par le biais des structures du Parti canadien ${ }^{117}$ et leur participation à la révolte (phase $\mathrm{C}$ ). Ces trois phases ne sont pas sans rappeler les trois degrés de conflit national définis par Maurice Séguin ${ }^{118}$ et la période de «maturation de la conscience collective» et d' «articulation indispensable» entre les élites et le «vrai peuple» décrite par Wallot ${ }^{119}$. Elles nous font penser également à l'analogie de «l'explosion» développée par Jean-Paul Bernard dans une brochure récente publiée par la Société historique du Canada ${ }^{120}$. Le plan stratégique des patriotes canadiens serait donc comparable à ce qu'a observé Hroch et conforme aux théories de communication et de mobilisation sociales décrites par Deutsch. Il comportait deux étapes: «la première, celle de l'agitation soi-disant légale; la seconde advenant l'échec de la première, impliqu[ait] le déclenchement d'une révolu$\operatorname{tion}^{121}$.»

Voilà donc une situation qui cadre bien avec le modèle dessiné par Miroslav Hroch et Karl Deutsch. Gellner l'assimilerait pour sa part au «nationalisme libéral occidental classique » parce que les différences entre les détenteurs du pouvoir (gentilité bureaucratique et militaire: le «peuple à l'anglaise») et ceux qui en sont privés (petite et moyenne bourgeoisie et le «vrai peuple»), tiennent principalement à leur appartenance culturelle. Voilà aussi une possibilité d'approche comparée très stimulante!

114. M. Hroch, op. cit., 161; F. Ouellet, «Les insurrections...», loc. cit.

115. G. Paquet et J.-P. Wallot, «Groupes sociaux...», loc. cit., 536 et 542.

116. F. Dumont, op. cit., 104 et ss.

117. R. Boily, op. cit.

118. Maurice Séguin, Histoire de deux nationalismes au Canada (Montréal, Guérin, 1997), Lecons IX et X; id., «Le double soulèvement de 1837 », dans J.-P. Bernard, Les Rébellions de 1837-1838. Les patriotes du Bas-Canada..., op. cit., 175-176.

119. J.-P. Wallot, «Révolution et réformisme...», loc. cit., 429-435; J.-P. Wallot et G. Paquet, «Groupes sociaux...», loc. cit., 522.

120. J.-P. Bernard, Les rébellions de 1837 et de $1838 \ldots$, op. cit.

121. F. Ouellet, «Les insurrections... », loc. cit., 207. 
Quant à la participation des couches populaires à la révolte, la fameuse phase $\mathrm{C}$ grâce à laquelle l'objectif de souveraineté nationale devait être atteint, la plupart des historiens de la rébellion dont Fernand Ouellet, Allan Greer et Elinor Kyte Senior, poursuivent une démarche similaire qui consiste à occulter l'objectif de la souveraineté dans les motivations profondes de la révolte. Il s'ensuit alors une argumentation tronquée car, comme l'écrivait justement le sociologue Marcel Rioux: «tout un pan de la réalité, le plus massif, le plus global, est passé sous silence: on a tendance à raisonner comme si le colonialisme et la domination n'existaient pas ${ }^{122}$.» Cela est très clairement énoncé chez Greer pour qui «la question vraiment intéressante, celle qui pose un véritable défi, est non pas de savoir pourquoi mais comment les habitants réussirent à rompre leur isolement, leur atomisation, pour devenir une force politique significative ${ }^{123} \gg$. Question proche de celle posée par Ouellet qui s'était demandé déjà «dans quelle mesure et pourquoi les couches populaires [avaient]-elles participé massivement au mouvement [et] quels [avaient été] le rôle des élites et leurs rapports avec les milieux urbains et ruraux ${ }^{124}{ }^{2}$. Il est à noter en effet que ce «pourquoi» chez Ouellet se réduit en réalité à un simple «comment».

Chez Ouellet, la question de la participation populaire a immédiatement reçu une réponse avec l'hypothèse de la manipulation des masses par les élites, conformément à un modèle esquissé par Boris Porchnev pour les soulèvements populaires en France au XVII ${ }^{e}$ siècle ${ }^{125}$. Hypothèse, devenue affirmation, reprise par Senior pour qui les masses ont constitué «une majorité silencieuse» soumise à «l'endoctrinement» des «phalanges intellectuelles et d'organisation de propagande ${ }^{126} »$. Greer ne suit pas Ouellet sur ce terrain, se refusant à porter un jugement sur les véritables motivations des patriotes. Comme Ouellet cependant, il tente un certain rapprochement avec les révoltes paysannes un peu partout dans le monde et à des périodes différentes, en particulier dans les sociétés d'ordre d'Ancien Régime. Il finit par chercher réponse à son «comment» dans la culture folklorique des paysans et dans certains rituels de la vie communautaire comme le charivari, la célébration du mai et dans l'exercice de leur esprit de révolte à l'intérieur des institutions paroissiales ${ }^{127}$.

122. Marcel Rioux, La question du Québec (Montréal, Parti pris, 1976), 72.

123. Allan Greer, Habitants et Patriotes. La rébellion de 1837 dans les campagnes du Bas-Canada (Montréal, Boréal, 1997), 29.

124. F. Ouellet, «Les insurrections...», loc. cit., 206.

125. Ibid., 215 et 206 .

126. E. K. Senior, op. cit., 30, 35.

127. A. Greer, op. cit., chap. 2 et 3. 
Ne faut-il pas se demander dès maintenant si ces références au modèle de Porchnev chez Ouellet et aux jacqueries du XVII ${ }^{\mathrm{e}}$ siècle chez Greer sont bien pertinentes? N'y aurait-il pas ici une erreur de perspective dans le questionnement? Il est vrai que ce modèle pourrait être universel, mais il ne peut être le seul modèle référentiel. La mise en comparaison ne devrait-elle pas se faire prioritairement avec les paysanneries qui ont participé effectivement aux mouvements d'indépendance nationale de leur pays?

La lecture des chapitres IV et V du livre de Greer intitulés «Le mouvement patriote et la crise du régime colonial» et «Deux nations en guerres » et celle d'un récent article publié dans le Bulletin d'histoire politique ${ }^{128}$, nous montrent que l'auteur n'a pas voulu aller dans ce sens, quoique parfois il nous en donne l'impression. En effet, il souligne bien au passage la parenté entre rébellion au Bas-Canada et révolutions libérales ailleurs à la même époque, mais sans jamais passer vraiment à l'analyse. Il ne retient pas non plus la dimension nationalitaire de toutes ces dernières, privilégiant la dynamique interne propre à toutes ces révoltes ${ }^{129}$. Selon cet éclairage, le Parti patriote est un «parti ethnique ${ }^{130}$ » engagé dans un conflit interethnique: « $\mathrm{Ce}$ combat qu'on semblait livrer pour la démocratie et l'indépendance nationale, n'était-il en fait qu'un conflit tribal entre Anglais et Français $[\ldots]^{131}$ ?»

La lutte nationale menée par les Patriotes ainsi assimilée à une manifestation d'hostilité contre «une minorité culturelle ${ }^{132}$ » permet à Greer de s'interroger sur la «xénophobie primaire ${ }^{133}$ » des Canadiens. Ouellet y avait fait allusion avant lui en écrivant au sujet des élites qu'elles «avaient appris aux classes populaires à reconnaître leurs ennemis: le gouvernement colonial et celui de la métropole, le capitaliste, l'émigré et en un mot, l'Anglais ${ }^{134}{ }^{\prime}$. Opinion, reprise entre autres par Senior et Trofimenkoff, qui avait fait s'écrier ainsi le sociologue Marcel Rioux: "Y a-t-il un seul peuple dominé de la terre auquel ses élites n'ont pas tenu pareil raisonnement ${ }^{135}$ ?»

Ouellet admet que la révolution de 1837 fut un phénomène d'émancipation nationale ayant largement pénétré les masses. Il ne va

128. A. Greer, «Reconsidérer la Rébellion de 1837-1838», Bulletin d'histoire politique, 7,1 (automne 1998): 29-40.

129. Ibid., 30-32.

130. A. Greer, op. cit., 118.

131. Ibid., 144.

132. Ibid.

133. Ibid., 168

134. F. Ouellet, «Les insurrections... », loc. cit., 216.

135. M. Rioux, op. cit., 72. 
pas plus loin dans cette voie. Sa thèse veut que les masses aient été manipulées par les élites qui ne parviennent pas à dépasser leurs intérêts de groupe. Même si Ouellet se refuse à l'admettre, le scénario qu'il décrit correspond globalement au modèle de «nationalisation » des sociétés qui embrasa l'Europe au XIX ${ }^{\mathrm{e}}$ siècle. Le procès d'intention fait aux élites par certains historiens à la suite de Ouellet est-il vraiment pertinent du point de vue de la théorie du nationalisme et de l'approche du Nation building? S'interroger sur le conservatisme des patriotes - thèse d'ailleurs contestée par Gérald Bernier et Daniel Salée ainsi que par Gilles Paquet et Jean-Pierre Wallot - nous apparaît secondaire par rapport au courant libéral et nationalitaire dont la rébellion de 1837 demeure un exemple, exemple conforme au modèle élaboré par les nombreux auteurs précités.

\section{CONCLUSION}

La majorité des auteurs qui ont écrit sur le nationalisme au XIX siècle lient l'apparition de la conscience nationale et l'émergence de la nation au phénomène de la transition. Cela est particulièrement vrai chez ceux qui appartiennent à l'école du Nation building, chez des marxistes comme Otto Bauer et Eric Hobsbawm; chez d'autres spécialistes de la question comme le philosophe Pierre-André Taguieff ${ }^{136}$ et même chez les praticiens de la psychologie sociale comme William Bloom $^{137}$.

Selon cette approche, la transition vers l'industrialisation et la transition vers le nationalisme vont de pair. Le mouvement nationalitaire n'apparaîtrait que dans des sociétés industrielles ou proto-industrielles, c'est-à-dire là où la structure socioprofessionnelle est complexe et où un système d'éducation hiérarchisé existe. Dans une telle société, il y a mobilité entre les classes et les professions et un réseau complexe de communication (la culture) grâce à une langue commune diffusée et unifiée par l'école. C'est pourquoi les enseignants et les intellectuels (journalistes et autres professions libérales) jouent un rôle si important dans la conscience nationale, la mobilisation sociale et la revendication d'un État national.

Dans cette perspective, la cléricalisation de tout le système d'enseignement au Québec, commencée sous l'Union et poursuivie avec la

136. Pierre-André Taguieff, «Le nationalisme des "nationalistes". Un problème pour l'histoire des idées en France», dans G. Delannoi et P.-A. Taguieff, dir., op. cit., 47-124.

137. William Bloom, Personnal Identity, National Identity and International Relations (Cambridge, Cambridge University Press, 1990). 
Confédération ${ }^{138}$, revêt une signification profonde et est un des éléments cruciaux du paradigme de la survivance. Paradigme à l'origine de la «culturalisation» de la question nationale et du phénomène politique après l'échec de la rébellion de 1837 . Il n'est pas inintéressant de remarquer que ce n'est qu'après 1945 que le mouvement de laïcisation de l'enseignement s'amorce à nouveau et avec lui l'affirmation nationalitaire du Québec. N'a-t-on pas dit avec à-propos que le premier gouvernement du Parti québécois en 1976 était «une république des professeurs »?

Jusqu'à la fin du XIX ${ }^{\mathrm{e}}$ siècle et même plus tard, le nationalisme reste donc avant tout le fait de ceux qui s'inscrivent dans le mouvement des nationalités et de ceux qui luttent pour la reconnaissance nationale de leur peuple. Il a peu à voir avec le chauvinisme et autres jingoïsmes apparus bien après les rébellions de 1837 .

La mise en comparaison que nous venons d'effectuer dans cet essai projette une lumière plus nuancée sur la question nationale québécoise qui apparaît désormais comme une manifestation outreatlantique du grand courant libéral et nationalitaire européen. La lutte de deux cultures pour le pouvoir emprunterait ainsi certains traits proches du modèle dit «nationalisme libéral occidental classique » défini par Gellner. Par ailleurs, la démarche des patriotes évoluant dans une structure de classes spécifique la rapprocherait du modèle des petites nations étudié par Hroch. Voilà deux avenues de recherche intéres-santes!

On peut conclure, en terminant, que le Québec s'inscrivait dans la normalité politique jusqu'en 1840. Après cette date, à cause de l'échec de sa révolution nationale, il sort pour ainsi dire de l'histoire et se marginalise comme nation en s'annexant à l'État canadien en 1867. Son existence politique comme peuple quitte alors les frontières d'une réalité encore possible pour entrer surtout dans le champ du discours idéologique. Se produit alors graduellement un phénomène de régression vers la culturalisation de la nation, comme instrument principal de la survivance.

138. André Labarrère-Paulé, Les instituteurs läques au Canada français, 1836-1900 (Québec, Les Presses de l’Université Laval, 1965). 